\title{
BMJ Open Influence of social deprivation on provision of bariatric surgery: 10-year comparative ecological study between two UK specialist centres
}

Shivam Bhanderi, ${ }^{1}$ Mushfique Alam, ${ }^{1}$ Jacob Henry Matthews, ${ }^{1}$ Gavin Rudge,${ }^{2}$ Hamish Noble, ${ }^{3}$ David Mahon, ${ }^{3}$ Martin Richardson, ${ }^{4}$ Richard Welbourn, ${ }^{3}$ Paul Super, ${ }^{4}$ Rishi Singhal ${ }^{4}$

To cite: Bhanderi S, Alam M, Matthews JH, et al. Influence of social deprivation on provision of bariatric surgery: 10-year comparative ecological study between two UK specialist centres. BMJ Open 2017;7:e015453. doi:10.1136/ bmjopen-2016-015453

- Prepublication history for this paper is available online. To view these files please visit the journal online (http://dx.doi. org/10.1136/bmjopen-2016015453).

6th Annual Scientific Meeting of the British Obesity \& Metabolic Surgery Society (BOMSS) 2015, and at the 20th World Congress of the International Federation for the Surgery of Obesity and Metabolic Disorders (IFSO) 2015.

Received 8 February 2017 Revised 5 June 2017 Accepted 22 June 2017

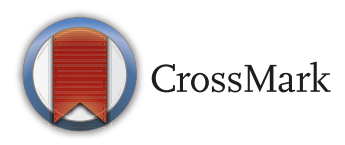

For numbered affiliations see end of article.

\section{Correspondence to}

Rishi Singhal;

rishi.singhal@heartofengland. nhs.uk

\section{ABSTRACT}

Objective To investigate the effect of residential location and socioeconomic deprivation on the provision of bariatric surgery.

Design Retrospective cross-sectional ecological study. Setting Patients resident local to one of two specialist bariatric units, in different regions of the UK, who received obesity surgery between 2003 and 2013.

Methods Demographic data were collected from prospectively collected databases. Index of Multiple Deprivation (IMD 2010) was used as a measure of socioeconomic status. Obesity prevalences were obtained from Public Health England (2006). Patients were split into three IMD tertiles (high, median, low) and also tertiles of time. A generalised linear model was generated for each time period to investigate the effect of socioeconomic deprivation on the relationship between bariatric case count and prevalence of obesity. We used these to estimate surgical intervention provided in each population in each period at differing levels of deprivation.

Results Data were included from 1163 bariatric cases (centre 1-414, centre 2-749). Incidence rate ratios (IRRs) were calculated to measure the associations between predictor and response variables. Associations were highly non-linear and changed over the 10-year study period. In general, the relationship between surgical case volume and obesity prevalence has weakened over time, with high volumes becoming less associated with prevalence of obesity.

Discussion As bariatric services have matured, the associations between demand and supply factors have changed. Socioeconomic deprivation is not apparently a barrier to service provision more recently, but the positive relationships between obesity and surgical volume we would expect to find are absent. This suggests that interventions are not being taken up in the areas of need. We recommend a more detailed national analysis of the relationship between supply side and demand side factors in the provision of bariatric surgery.

\section{INTRODUCTION}

Obesity leads to an increased risk of developing a plethora of comorbid diseases. ${ }^{1-4}$ The
Strengths and limitations of this study

- This study compares the caseload of two UK specialist bariatric centres over a 10-year period between 2003 and 2013.

- Estimates of regional obesity prevalence and measures of socioeconomic deprivation are from Public Health England 2006 and the 2010 Index of Multiple Deprivation, which are the most recent and reliable sources available.

- A generalised linear model is developed to predict expected caseload based on local obesity prevalence and examines the effect of socioeconomic deprivation on this relationship, which includes adjustment for the inherent interaction between deprivation and obesity.

- The model however was unable to adjust for other factors known to be likely influences on both the demand for and provision of bariatric services, such as comorbidities and ethnicity.

- Finally, this study may be subject to selection bias as data were only collected for those patients who had received a bariatric procedure, and not all patients who were referred to specialist weight management services.

prevalence of obesity has reached epidemic proportions across the globe. The WHO stated that around 2.8 million people worldwide die from the consequences of obesity. Furthermore, the WHO estimates that by 2030, two billion people will be overweight and one billion people will be obese. ${ }^{56}$ In the UK, the prevalence of obesity has increased from approximately $15 \%$ in 1993 to $27 \%$ in $2015 .^{7}$ As a result, obesity is a significant cause of healthcare expenditure. In the UK, the cost of obesity to the National Health Service (NHS) in 2007 was estimated to be $£ 3.2$ billion, 8 and in 2013 the UK Department of Health estimated the cost to be over $£ 5$ billion per year. ${ }^{9}$ 
Bariatric surgery has been proven to be a cost-effective method to treat adult obesity and its associated comorbidities. ${ }^{10}$ A systematic review and meta-analysis conducted by Buchwald et al in 2004 reported that resolution or improvement of diabetes can be seen in up to $86 \%$ of patients following bariatric surgery. ${ }^{11}$

Previous studies have demonstrated that high socioeconomic deprivation correlates with a higher prevalence of obesity in developed countries such as the USA and the UK. ${ }^{12}$ It is suggested that lower socioeconomic groups are more exposed to environmental factors which promote obesity, and are less able to modify their risk factors due to higher financial pressures and a lower standard of education. $^{13}$

A prospective cohortstudy of patients in Australia showed socioeconomic disparities in the provision of bariatric surgery, with patients able to afford private health insurance more likely to receive surgery, compared with those in lower socioeconomic groups. ${ }^{14}$ Similar findings were reported from two earlier US studies, which concluded that a significant proportion of those who would benefit from bariatric surgery are less likely to receive it due to socioeconomic deprivation. ${ }^{15-17}$ Insurance-based healthcare provision may partially explain these disparities, although there is conflicting evidence. ${ }^{18} 19$ However, research on populations with free universal healthcare also suggests that there are disparities in the uptake of bariatric surgery with regard to socioeconomic status. In both Canada and Sweden, patients eligible for surgery were more likely to be in a lower socioeconomic group, with significant sociodemographic differences present between those eligible for surgery and recipients of surgery. ${ }^{20} 21$

In order to standardise access to bariatric surgery in the UK, the National Institute for Health and Care Excellence (NICE) provided recommendations and eligibility criteria for the provision of bariatric surgery to obese patients. ${ }^{22}$ Decisions regarding the provision of specialist weight management services to obese patients lie with local healthcare funding bodies. However, there is concern that constraints on regional funding within the NHS mean that despite being eligible, many patients are not receiving bariatric surgery when indicated. ${ }^{23}$

This has led to the emergence of a 'postcode lottery' in bariatric surgery, in which the likelihood that an eligible patient will receive surgery depends on their location of residence and not just their clinical need or the fulfilment of criteria. ${ }^{24} 25$

The present study aims to investigate the role of socioeconomic deprivation on the regional provision of bariatric surgery by comparing the 10-year caseload of two specialist high-volume centres.

\section{METHODS}

\section{Study design and setting}

A retrospective cross-sectional ecological study design was used to compare the provision of bariatric surgery between two UK regions over a 10-year period (20032013). The design involved retrospectively investigating the associations between geographical density of bariatric cases with both obesity prevalence and socioeconomic deprivation. The centres were in Birmingham in the West Midlands (Birmingham Heartlands Hospital, Heart of England NHS Foundation Trust) and in South West England (Musgrove Park Hospital, Taunton and Somerset NHS Foundation Trust).

\section{Participants}

Two centres were chosen for which there were sufficient demographic and geographical data available for consecutive patients who had received bariatric surgery over a 10-year period (2003-2013). These centres were deemed appropriate for the study as they are within two different health economies, are both similarly well established and have similar sized bariatric teams. Finally, both are fully subject to NICE guidelines on provision of obesity services but are different in sociodemographic distribution, which allows for investigation into whether this difference is associated with a difference in provision of surgery.

We were interested in surgery in populations with reference to population characteristics. This is problematic as hospitals do not have agreed catchment areas based on residence for most services, and may provide services for people living some distance away if they have no local provider. We therefore determined notional catchment areas where virtually all treated cases resident there would have been treated in one of our study centres. Analysis of national Hospital Episode Statistics data identified suitable areas. These were coterminous with existing administrative boundaries and were geographically contiguous, resulting in two separately isolated health economies containing a centre for bariatric surgery that served separate population groups. In the case of the West Midlands, our area was defined by residence in the Local Authority areas of Birmingham City Council and the Metropolitan Borough Council of Solihull. In the case of the SouthWest, our area was defined by the local authority areas of North Somerset Council contiguously south to Plymouth City Council. Any patients who received surgery at either of the two centres selected, but were not resident in either of the notional catchment areas, were excluded from the study. As the West Midlands catchment area was smaller, we expected there to be fewer observations from this centre compared with the South-West, despite the similar overall caseload of both bariatric units.

\section{Variables and data sources}

Demographic variables collected included age, gender and body mass index (BMI). The area of residence of the patients was used to obtain the Index of Multiple Deprivation (IMD) score and the most recent obesity prevalence estimates (Public Health England, 2006) ${ }^{26}$ for the relevant Middle-layer Super Output Areas (MSOAs). ${ }^{27}$ The IMD score is a measure of socioeconomic status. It is a multidomain score used by the Office of National 
Statistics which takes into account a range of indicators, including those of economic, social and housing factors. A higher IMD score for an area indicates higher socioeconomic deprivation.

MSOAs are units of census geography that are more homogeneous in terms of demographics and socioeconomic status than other areas of administrative geography such as electoral wards. Furthermore, they are the only population aggregations for which there are reliable socioeconomic data, obesity prevalence estimates and demographic data. As an indication of size, English MSOAs had a mean resident population of 7703 in $2010 .{ }^{28}$

\section{Statistical methods}

The data for each region were used to construct a generalised linear model to test the association between the count of bariatric cases in each MSOA with deprivation and obesity prevalence. The units of analysis in the model were MSOAs and our models predicted counts of surgical cases. We had to adjust for the impact of time as services and the commissioning arrangements that underpin them evolved. We split the cases into tertiles of time (referred to as epochs hereafter) from the earliest observation to the latest in each centre. A generalised linear model assuming a Poisson distribution was used as the counts of individual cases in such small areas were small integers. The models incorporated quadratic terms for both obesity prevalence and socioeconomic deprivation as well as an interaction term for the interaction between deprivation and obesity prevalence and an offset term (a mid-period population estimate for the MSOA). The model results were then used to make a series of estimated counts of surgical cases for each tertile of socioeconomic deprivation, in each centre and for each epoch. The estimates were used to evaluate the relationships were between deprivation, obesity prevalence and surgical case volume, and their evolution over time. To geographically visualise the relationships between bariatric case count and socioeconomic data, Geographical Information Systems software (ArcGIS V.10.0) was used to map the geographical distribution of bariatric cases in each centre against estimated MSOA obesity prevalence and median IMD score.

\section{RESULTS}

\section{Demographics}

At centre 1, 1875 patients underwent bariatric surgery during the study period. Of these, 414 were resident in the derived catchment area. Fourteen further patients were excluded due to missing or incomplete data, leaving 414 cases included for analysis. For centre 2, there were 1196 documented cases with complete case note data, of which 749 were resident in our study area. Therefore, data were collected from 1163 bariatric cases in total (414 from centre 1 and 749 from centre 2) which were geographically mapped and included in the statistical analysis.

Table 1 summarises the demographics of the patients included in the study. The age distribution of patients treated in centre 1 was significantly lower than in centre 2 (median age 45 years vs 46 years, $\mathrm{p}=0.01$; Wilcoxon rank test). The majority of included patients in both centres were women $(76.7 \%$ in centre 1 vs $77.6 \%$ in centre 2$)$. The median BMI of patients in centre 1 was significantly higher than in centre $2\left(52.0 \mathrm{~kg} / \mathrm{m}^{2}\right.$ vs $48.7 \mathrm{~kg} / \mathrm{m}^{2}, \mathrm{p}<0.01$; Wilcoxon rank test).

The patients treated in centre 1 were from areas of higher obesity prevalence than in centre 2 (median MSOA obesity prevalence $27.2 \%$ vs $25.8 \%, \mathrm{p}<0.05)$. Furthermore, patients treated at centre 1 also lived in more deprived areas when compared with those from centre 2 (median IMD score 26.00 vs $18.83, \mathrm{p}<0.05$, Wilcoxon rank test).

\section{Statistical modelling}

Figure 1 geographically displays the relationships between case density, estimated MSOA obesity prevalence and median MSOA IMD score for both centres. The maps appear to show that most bariatric patients live in regions of both higher obesity prevalence and deprivation, but the proportion of patients for which this is the case is unequal between both regions.

Statistical analysis using a generalised linear model found that the relationships between bariatric surgery volume and obesity and deprivation were non-linear. This makes the interpretation of the coefficients alone (shown in tables 2 and 3 ) difficult. We incorporated an interaction term between obesity prevalence and deprivation and tested its association with surgery uptake along with the other variables. The statistical significance of this term further complicates interpretation. For this reason, we made three predictions for each centre and

Table 1 Demographics of the two study populations

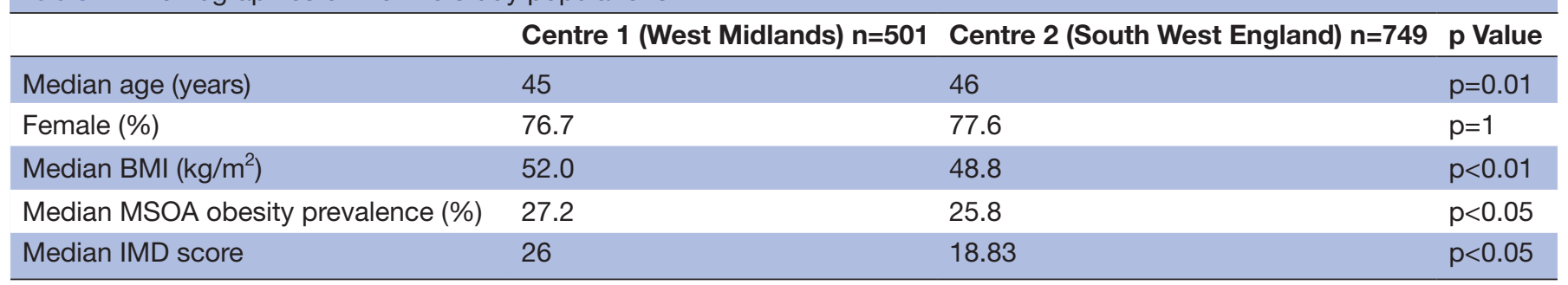

BMI, body mass index; IMD, Index of Multiple Deprivation; MSOA, Middle-layer Super Output Area. 


\section{CENTRE 1}
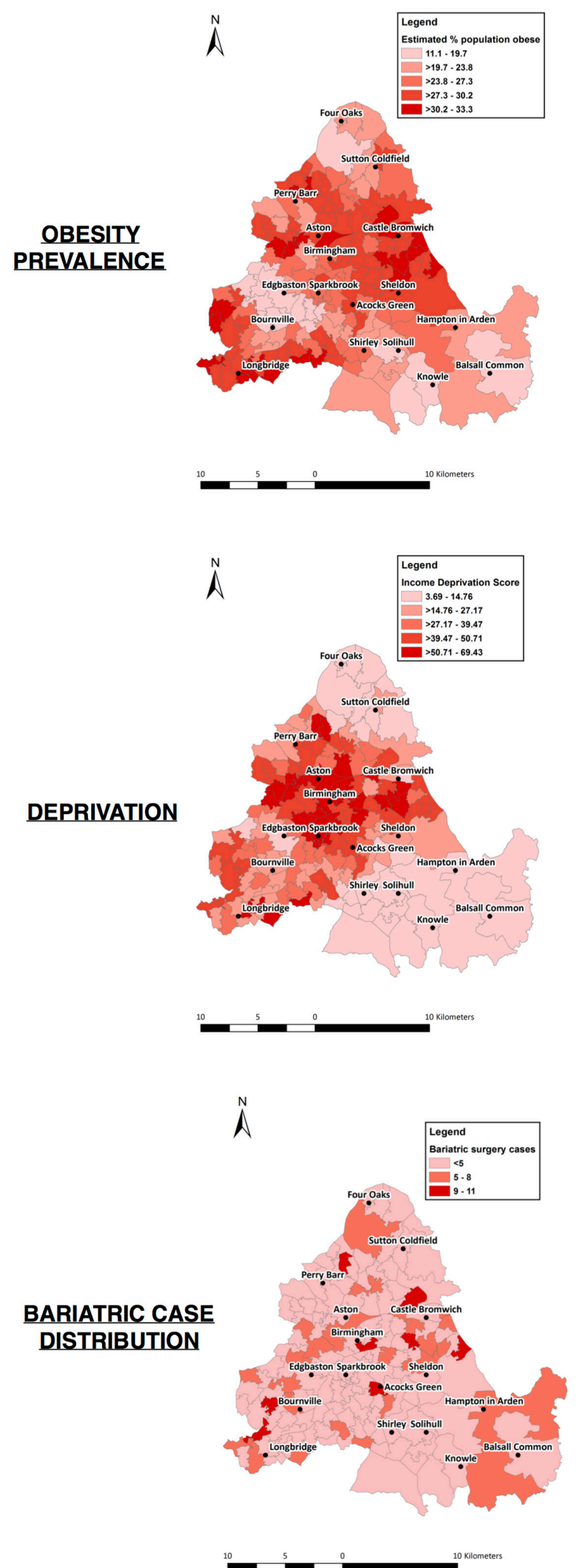

\section{CENTRE 2}

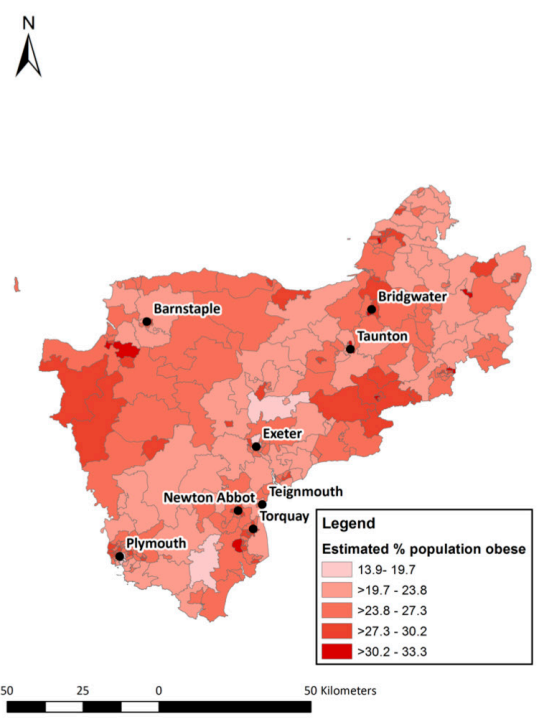

$\bigwedge^{N}$
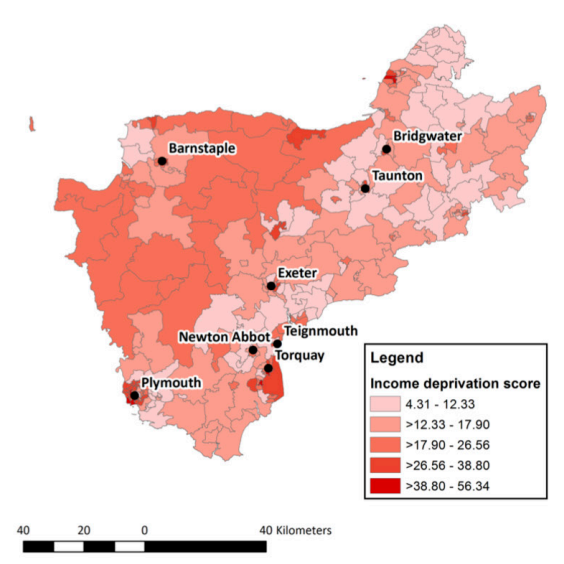

$\AA^{N}$

Figure 1 Geospatial mapping of cases onto maps of obesity prevalence, socioeconomic deprivation and local case density. 
epoch showing graphically how many cases would be expected in our populations, assuming some variables were held constant and estimated surgical case volume at different prevalence rates of obesity. To estimate the effect of socioeconomic deprivation, we ran predictions fixing deprivation at three levels: lower tertile, median and upper tertile. In a service where surgical uptake was sensitive to demand and where there was equal access across socioeconomic groups, we expect a consistent positive relationship between obesity prevalence and volume. Furthermore, the strength of this relationship should not vary between areas of high and low deprivation, once obesity had been accounted for.

Applying this model to Birmingham (figure 2) showed that in the first epoch of observation, the service was providing more surgery in areas of high obesity that were at or around the median level of deprivation. Areas that were more or less deprived than the median saw a weaker relationship between obesity prevalence and surgery. Interestingly, the results changed over time (figures 3 and 4). In the later epochs, there was a markedly weaker relationship between obesity prevalence and surgical case volume, suggesting that as the service matured, patients from areas of higher obesity rates were not necessarily more likely to receive surgery. Indeed, all other things being equal, our model predicted the highest case counts in areas of lowest obesity prevalence.
Independent of other factors, deprivation was positively associated with surgical case volume.

In the South-West, in epoch 1 (figure 5), the relationship between local obesity prevalence and incidence of surgery case was highly positive, except for deprived areas. Our model estimated that people in deprived areas had much less surgery irrespective of local obesity prevalence. As the service developed the associations changed. In epochs 2 and 3 (figures 6 and 7), our models estimated that the relationship between obesity and surgical volume was ' $U$ ' shaped with higher volumes in both low and high obesity areas. Latterly, the association has become largely flat, with the exception of people living in more deprived areas. These areas appear to have higher case counts relative to less deprived locations, and volumes are associated with local obesity prevalence.

\section{DISCUSSION}

\section{Statement of principal findings}

Statistical modelling has demonstrated that the uptake of bariatric surgery appears to correlate with obesity prevalence in both UK centres, but this relationship has weakened over time. However, both centres differed in their relationships between surgical volume and deprivation independent of obesity. Overall, the differences

Table 2 Table showing incidence rate ratios (IRRs) for the interactions between socioeconomic deprivation and obesity prevalence in three epochs for Birmingham

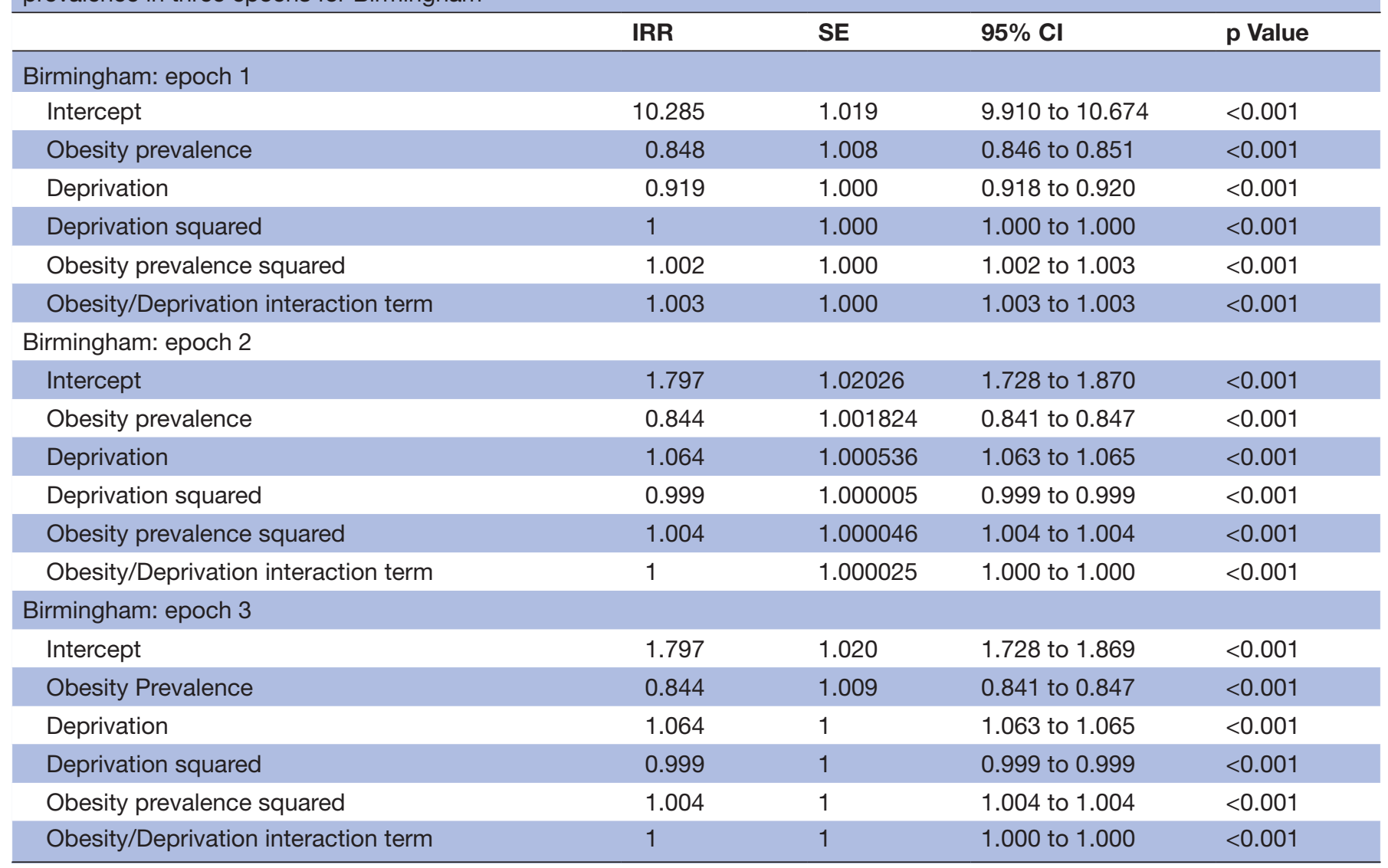


Table 3 Table showing incidence rate ratios (IRRs) for the interactions between socioeconomic deprivation and obesity prevalence in three epochs for the South-West

\begin{tabular}{|c|c|c|c|c|}
\hline & IRR & SE & $95 \% \mathrm{Cl}$ & p Value \\
\hline \multicolumn{5}{|l|}{ South-West: epoch 1} \\
\hline Intercept & 0.065 & 1.035 & 0.061 to 0.070 & $<0.001$ \\
\hline Obesity prevalence & 0.958 & 1.003 & 0.953 to 0.963 & $<0.001$ \\
\hline Deprivation & 1.179 & 1.001 & 1.177 to 1.180 & $<0.001$ \\
\hline Deprivation squared & 0.999 & 1 & 0.999 to 0.999 & $<0.001$ \\
\hline Obesity prevalence squared & 1.005 & 1 & 1.004 to 1.005 & $<0.001$ \\
\hline Obesity/Deprivation interaction term & 0.996 & 1 & 0.996 to 0.996 & $<0.001$ \\
\hline \multicolumn{5}{|l|}{ South-West: epoch 2} \\
\hline Intercept & 7.771 & 1.027 & 7.376 to 8.186 & $<0.001$ \\
\hline Obesity prevalence & 0.788 & 1.002 & 0.784 to 0.791 & $<0.001$ \\
\hline Deprivation & 1.038 & 1.001 & 1.036 to 1.039 & $<0.001$ \\
\hline Deprivation squared & 0.998 & 1 & 0.998 to 0.998 & $<0.001$ \\
\hline Obesity prevalence squared & 1.004 & 1 & 1.004 to 1.005 & $<0.001$ \\
\hline Obesity/deprivation interaction term & 1.002 & 1 & 1.002 to 1.003 & $<0.001$ \\
\hline \multicolumn{5}{|l|}{ South-West: epoch 3} \\
\hline Intercept & 2.327 & 1.029 & 2.201 to 2.460 & $<0.001$ \\
\hline Obesity prevalence & 0.883 & 1.002 & 0.879 to 0.887 & $<0.001$ \\
\hline Deprivation & 1.019 & 1.001 & 1.017 to 1.020 & $<0.001$ \\
\hline Deprivation squared & 0.997 & 1 & 0.997 to 0.997 & $<0.001$ \\
\hline Obesity prevalence squared & 1.001 & 1 & 1.001 to 1.001 & $<0.001$ \\
\hline Obesity/deprivation interaction term & 1.005 & 1 & 1.005 to 1.006 & $<0.001$ \\
\hline
\end{tabular}

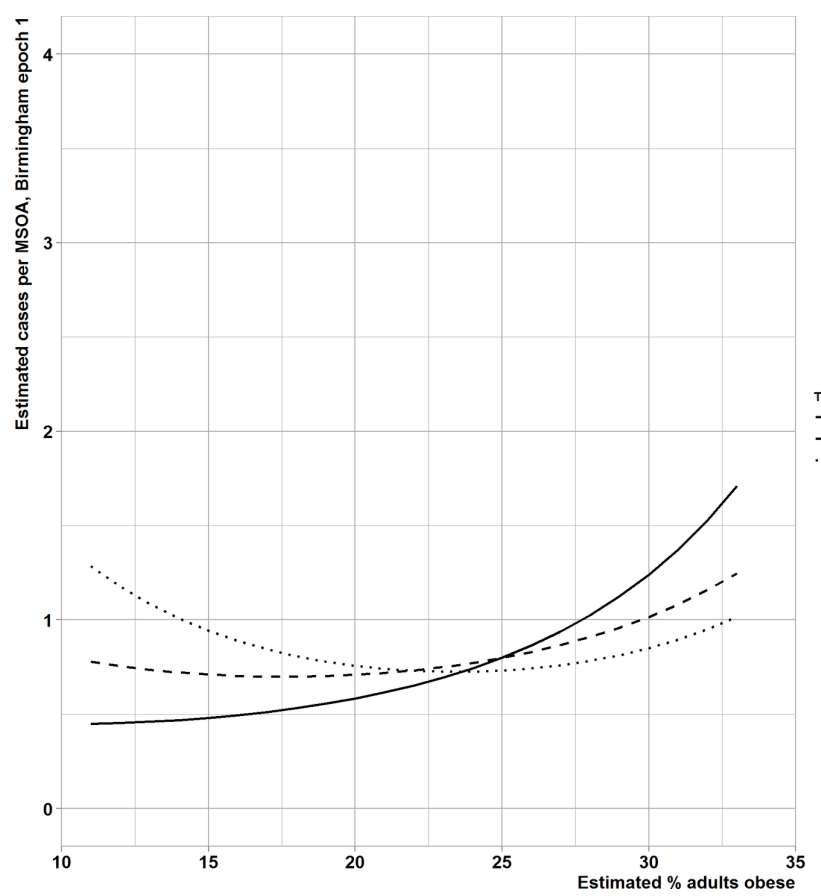

Figure 2 Modelled association between local obesity prevalence and predicted bariatric case count per Middlelayer Super Output Area (MSOA), at tertiles of deprivation, Birmingham epoch 1.

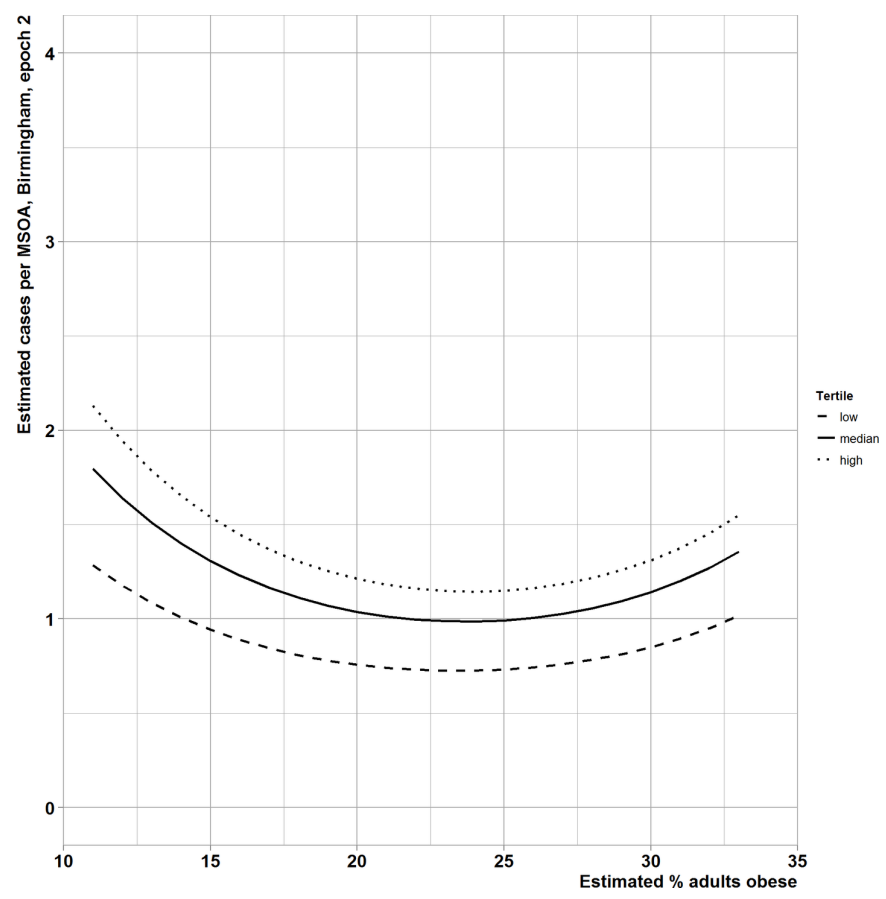

Figure 3 Modelled association between local obesity prevalence and predicted bariatric case count per Middlelayer Super Output Area (MSOA), at tertiles of deprivation, Birmingham epoch 2. 


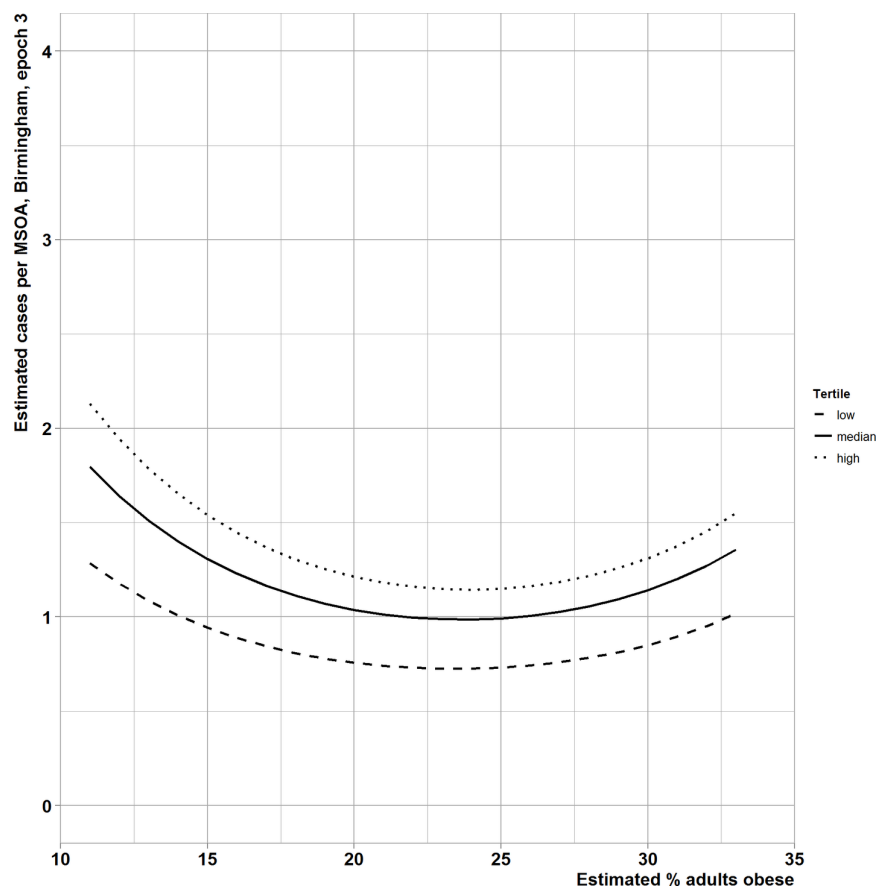

Figure 4 Modelled association between local obesity prevalence and predicted bariatric case count per Middlelayer Super Output Area (MSOA), at tertiles of deprivation, Birmingham epoch 3.

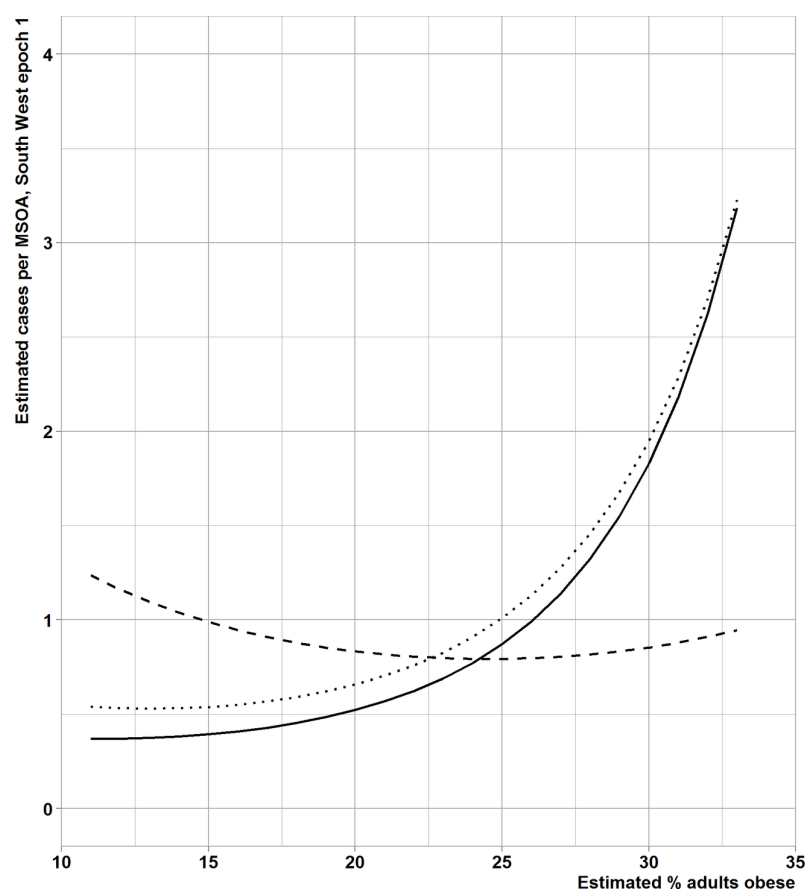

Figure 5 Modelled association between local obesity prevalence and predicted bariatric case count per Middlelayer Super Output Area (MSOA), at tertiles of deprivation, South-West epoch 1.

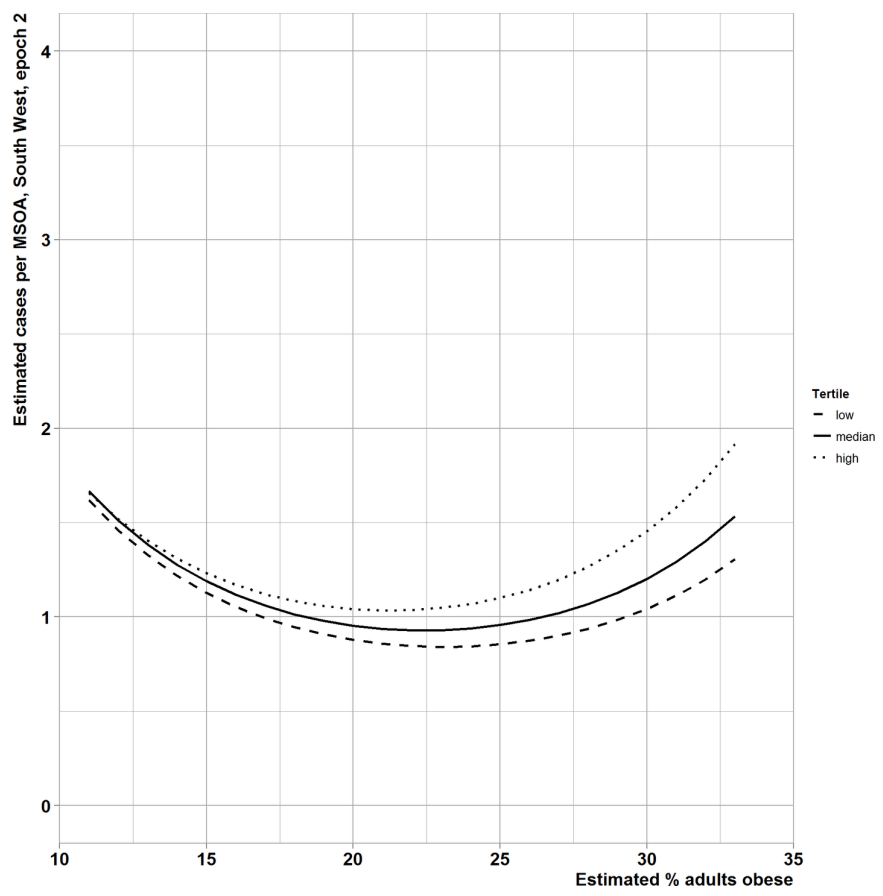

Figure 6 Modelled association between local obesity prevalence and predicted bariatric case count per Middlelayer Super Output Area (MSOA), at tertiles of deprivation, South-West epoch 2.

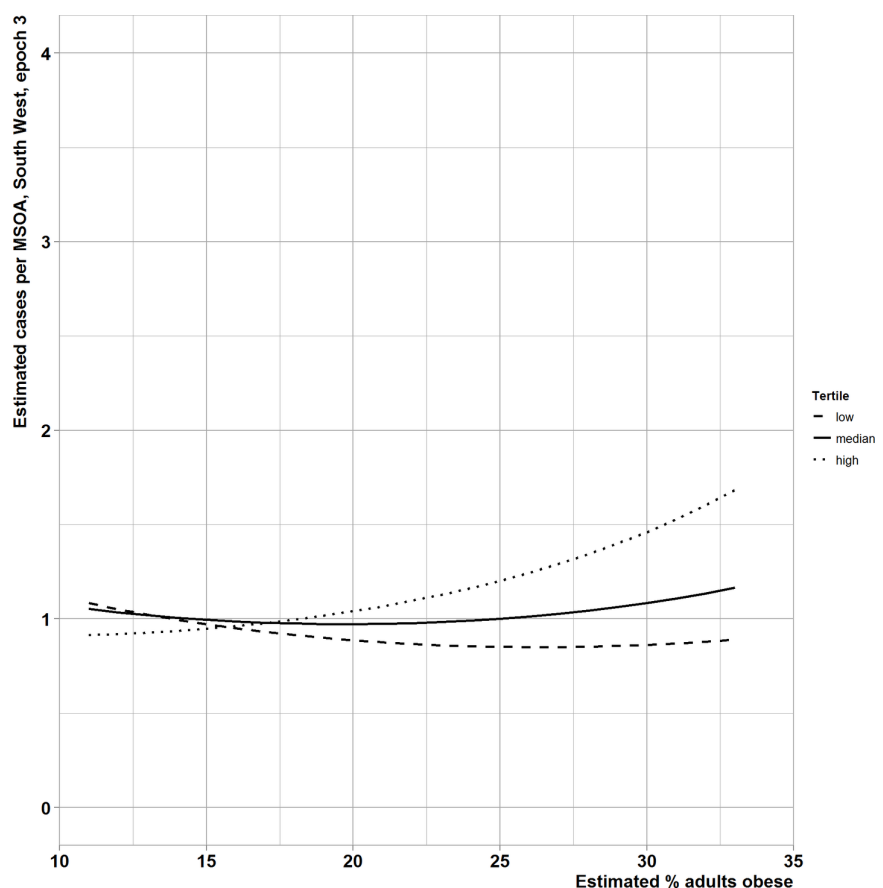

Figure 7 Modelled association between local obesity prevalence and predicted bariatric case count per Middlelayer Super Output Area (MSOA), at tertiles of deprivation, South-West epoch 3. 
in these relationships between the two centres studied suggest variability in access to bariatric surgery.

\section{Meaning of the study: possible explanations and implications for clinicians and policy-makers}

Eligibility recommendations from $\mathrm{NICE}^{22}$ aim to standardise the provision of bariatric surgery throughout the UK to ensure that the treatment is used for the correct patients, and also to ensure equality of access independent of other factors. However, demographic differences between regions may result in regional centres facing differing demands on their bariatric services. The requirement to meet the health needs of patients with other illnesses will also affect healthcare funding for a regional population.

In a model of bariatric provision, we would hope to see a fairly constant association between obesity prevalence and bariatric surgery use even after adjusting for other variables. Where we see a non-constant association this could potentially indicate situations where there is less equity in service access. In our data, we see that there appears to be a growing disconnect between obesity prevalence and surgical volume in both centres. Furthermore, this disconnect seems to grow further as the level of socioeconomic deprivation decreases, independent of obesity prevalence. Indeed, in our South-West centre we see a strong positive association between demand and provision in deprived areas, and a less convincing relationship in less deprived populations.

A crude interpretation of our findings could point to possible inequalities to access in centre 1 , however, we must temper our conclusions with regard to the many other supply and demand side factors that can affect this relationship. The higher prevalence of obesity in the region of centre 1 suggests an overall higher demand for bariatric surgery among this population. The excess demand over the supply of bariatric surgery may contribute to the emergence of bias in the selecting of patients for referral. In addition, differences in consulting behaviours between socioeconomic and ethnic groups may vary between the two regions, resulting in differences between referral patterns from primary care. Furthermore, differences in surgical practice between the two centres, for example, if one centre had a higher propensity to operate than the other, may skew the results of this study. However, this would suggest variation in adherence to NICE guidelines between the two regions.

Referral behaviours and patterns among general practitioners may differ between the two regions. Certain primary care practices may be more or less likely to refer patients for bariatric surgery and these may be associated with the socioeconomic conditions in which they are located. The SOCCER study into referral patterns to weight management services across 33 practices in Canada concluded that the referral behaviours of general practitioners are a barrier to access for patients to specialist weight management services. ${ }^{29}$ However, there may also be differences in both the number and proportion of patients that are referred to private providers operating in the two study regions, as these patients were not included in either sample.

However, total demand for bariatric surgery in both centres was not investigated by the present study, as only patients who received surgery were analysed. Further studies investigating centre capacity may yield conclusions regarding supply and demand of bariatric services.

Differences in local commissioning arrangements, which were primarily set by the primary care sector during the study period, have possibly lead to differences in the provision of bariatric surgery and the pathways into specialist weight management services in general. A survey of 49 Primary care trusts (PCTs) in 2011 found that only $35 \%$ of the 49 PCTs that responded had referral policies that matched NICE guidelines in all respects. $47 \%$ of PCTs had placed extra criteria on top of those suggested by NICE or had interpreted the national guidelines more stringently. ${ }^{23}$ The main reason for this is thought to be due to a lack of funding. ${ }^{30}$

\section{Strengths and weaknesses of the study}

This study had a number of limitations. The most important of these is a selection bias in that data were collected retrospectively from databases of patients who had received bariatric surgery. As a result, patients who were referred to specialist weight management services in either centre, but did not receive surgery for any other reason (unsuitable for surgery, patient refusal etc) were not included.

Furthermore, the role of the private sector in either of the two studies was not investigated due to a lack of reliable data. Indeed, data sources such as the National Bariatric Surgery Registry do not collect any data pertaining to residential location, therefore locally resident patients who received bariatric surgery privately are not able to be identified. The completeness of the remaining data in such registries for private patients is also not guaranteed.

Second, there are likely to be several other factors that influence both the demand for and provision of bariatric surgery in the two regions studied. These include referral behaviours of primary care providers, patient ethnicity and the presence of comorbidities. For example, estimated type 2 diabetes prevalence in adults is different in the two populations. In North Somerset and Plymouth the prevalence amongst those aged over 17 years is estimated as $5.54 \%$ whereas in Birmingham it is $7.61 \% .^{31}$ Although surgical volume was judged to be similar in the two regions selected for this study, the certain variety in the size of bariatric units across the UK will affect the generalisability of the results of this study to the rest of the country.

Unfortunately, the authors were unable to reliably obtain data on the treatment history of included patients prior to surgical intervention, such as weight loss via conservative measures which is suggested by NICE prior to any bariatric surgery. IMD score and Public Health England obesity estimates, although the most recent 
available, were from 2010 and 2006, respectively. We used a cross-sectional estimate of obesity in all of our populations, when clearly obesity rates are changing constantly. We assume, although cannot prove conclusively, that obesity rates have been generally rising. This raises the question of the validity of using a cross-sectional estimate in this work. The alternative would have been to model obesity prevalence over time. However, the precision of such an estimate would make the use of it in a model statistically difficult. We were able however to model the changes in the overall relationships over time by making models for each epoch. This was a pragmatic choice rather than performing a conventional time series analysis, but we did succeed in showing that the modelled associations changed over time in both centres and in slightly different ways.

There is a paucity of data on prevalence of BMI $>40$ in the population and so we have used BMI $>30$ as an indicative variable. This would appear reasonable, as it has been shown from data from Health Survey for England that the UK's median BMI has increased over time, but there has been a larger increase in the 95 th percentile. ${ }^{32}$ Nonetheless, there remains an assumption in this study that the relationship between BMI $>30$ and BMI $>40$ is more or less constant across different regional populations.

Also of note is the assumption in this study that a patient from an area of high socioeconomic deprivation belongs to a lower socioeconomic group, which may not always be the case.

\section{CONCLUSION}

In summary, the present study demonstrates an example of variation in access to bariatric surgery based on residential location. This is the first statistical evidence that there is a geographically variable relationship between the apparent need and provision of surgery. This supports recent concerns from the Royal College of Surgeons of England that access to bariatric services is inconsistent and dependent on geographical location. ${ }^{33}$ Whether or not this disparity in provision is due to undersupply of bariatric services, differences in referral patterns or other variables requires further investigation.

In an attempt to reduce disparity and to increase the provision of bariatric services throughout the UK, the responsibility for funding of bariatric surgery was allocated to specialised commissioning through NHS England in 2013. ${ }^{34}$ However, there are now imminent plans to devolve this service back to the local Clinical Commissioning Groups (formerly PCTs), with the potential for the reintroduction of inequalities in access to service. ${ }^{35}$

With the rising prevalence of obesity and the increasing future demand for bariatric surgery, this study highlights the need for an evidence-based approach to delivery of bariatric services. As a nation, we spend a large amount of money on the treatment of obesity, including bariatric surgery and much more money on treating the consequences of obesity. In this paper, we argue for a more scientific approach to understanding the complex relationship between supply and demand for bariatric treatment. We do not propose that we have built a definitive model of these factors in this simple observational study. However, given the policy imperative of providing treatment for those most in need equitably, we conclude that a much larger study investigating more demographic variables and in a larger study population, but with a broadly similar methodological approach, could usefully inform service development.

\section{Author affiliations}

${ }^{1}$ Foundation Year Doctor, West Midlands Deanery, Birmingham, UK

${ }^{2}$ Department of Public Health, Epidemiology and Biostatistics, University of Birmingham, Birmingham, UK

${ }^{3}$ Department of Upper Gl and Bariatric Surgery, Musgrove Park Hospital, Taunton, UK ${ }^{4}$ Upper Gl and Bariatric Unit, Heart of England NHS Foundation Trust, Birmingham, UK

Software Statistical analyses were conducted using RStudio. ArcGIS V.10.0 was used as geographical information systems software.

Contributors RS, RW and GR conceptualised the study. RW, RS, PS, MR, HN and DM collected prospective data for use in the study. GR conducted statistical analyses and mapping work. SB, MA and JM prepared the initial manuscript drafts, which were subsequently edited by all authors. All authors agreed to submission. $\mathrm{RS}$ is the guarantor for the study.

Funding GR has received funding via the NIHR CLAHRC West Midlands programme to provide statistical support for studies carried out by the CLAHRC initiative, including this particular study.

Disclaimer The lead author (the manuscript's guarantor) affirms that the manuscript is an honest, accurate and transparent account of the study being reported; that no important aspects of the study have been omitted and that any discrepancies from the study as planned (and, if relevant, registered) have been explained.

Competing interests None declared.

Patient consent Detail has been removed from this case description/these case descriptions to ensure anonymity. The editors and reviewers have seen the detailed information available and are satisfied that the information backs up the case the authors are making.

Provenance and peer review Not commissioned; externally peer reviewed.

Author note All authors, external and internal, had full access to all of the data (including statistical reports and tables) in the study and can take responsibility for the integrity of the data and the accuracy of the data analysis.

Open Access This is an Open Access article distributed in accordance with the Creative Commons Attribution Non Commercial (CC BY-NC 4.0) license, which permits others to distribute, remix, adapt, build upon this work non-commercially, and license their derivative works on different terms, provided the original work is properly cited and the use is non-commercial. See: http://creativecommons.org/ licenses/by-nc/4.0/

(C) Article author(s) (or their employer(s) unless otherwise stated in the text of the article) 2017. All rights reserved. No commercial use is permitted unless otherwise expressly granted.

\section{REFERENCES}

1. Ashrafian $H$, le Roux CW, Darzi A, et al. Effects of bariatric surgery on cardiovascular function. Circulation 2008;118:2091-102.

2. Ashrafian $\mathrm{H}$, Athanasiou $\mathrm{T}$, le Roux $\mathrm{CW}$. Heart remodelling and obesity: the complexities and variation of cardiac geometry. Heart 2011;97:171-2.

3. Fenske W, Athanasiou T, Harling L, et al. Obesity-related cardiorenal disease: the benefits of bariatric surgery. Nat Rev Nephrol 2013;9:539-51. 
4. Ashrafian $\mathrm{H}$, Ahmed K, Rowland SP, et al. Metabolic surgery and cancer: protective effects of bariatric procedures. Cancer 2011;117:1788-99

5. Kelly T, Yang W, Chen CS, et al. Global burden of obesity in 2005 and projections to 2030. Int J Obes 2008;32:1431-7.

6. World Health Organisation. 2013. Obesity and overweight, fact sheet no. 311. http://www.who.int/mediacentre/factsheets/fs311/en.

7. NHS Digital. Health Survey for England, 2015. 2016 http://www. content.digital.nhs.uk/catalogue/PUB22610.

8. Allender S, Rayner M. The burden of overweight and obesity-related ill health in the UK. Obes Rev 2007;8:467-73.

9. HM Government. Healthy lives healthy people: our strategy for public health in England. 2010 https://www.gov.uk/government/uploads/ system/uploads/attachment_data/file/216096/dh_127424.pdf.

10. Colquitt JL, Pickett K, Loveman E, et al. Surgery for weight loss in adults. Cochrane Database Syst Rev 2014;8:CD003641.

11. Buchwald $\mathrm{H}$, Avidor $\mathrm{Y}$, Braunwald $\mathrm{E}$, et al. Bariatric surgery: a systematic review and meta-analysis. JAMA 2004;292:1724-37.

12. El-Sayed AM, Scarborough P, Galea S. Unevenly distributed: a systematic review of the health literature about socioeconomic inequalities in adult obesity in the United Kingdom. BMC Public Health 2012;12:18.

13. Levine JA. Poverty and obesity in the US. Diabetes 2011;60:2667-8.

14. Korda RJ, Joshy G, Jorm LR, et al. Inequalities in bariatric surgery in Australia: findings from 49,364 obese participants in a prospective cohort study. Med J Aust 2012;197:631-6.

15. Wallace AE, Young-Xu Y, Hartley D, et al. Racial, socioeconomic, and rural-urban disparities in obesity-related bariatric surgery. Obes Surg 2010;20:1354-60.

16. Birkmeyer NJ, Gu N. Race, socioeconomic status, and the use of bariatric surgery in Michigan. Obes Surg 2012;22:259-65.

17. Martin M, Beekley A, Kjorstad R, et al. Socioeconomic disparities in eligibility and access to bariatric surgery: a national populationbased analysis. Surg Obes Relat Dis 2010;6:8-15.

18. Alexander JW, Goodman HR, Martin Hawver LR, et al. The impact of medicaid status on outcome after gastric bypass. Obes Surg 2008:18:1241-5.

19. Durkin AJ, Bloomston M, Murr MM, et al. Financial status does not predict weight loss after bariatric surgery. Obes Surg 1999;9:524-6.

20. Padwal RS, Chang HJ, Klarenbach S, et al. Characteristics of the population eligible for and receiving publicly funded bariatric surgery in Canada. Int J Equity Health 2012:11:54.

21. Memarian E, Calling S, Sundquist K, et al. Sociodemographic differences and time trends of bariatric surgery in Sweden 19902010. Obes Surg 2014;24:2109-16.

22. National Institute for Health and Care Excellence. 2006. Obesity: The prevention, Identification, assessment and management of overweight and obesity in adults and children. clinical guideline 43 . http://www.nice.org.uk/Guidance/CG43.

23. Welbourn R, le Roux CW, Owen-Smith A, et al. Why the NHS should do more bariatric surgery; how much should we do? BMJ 2016;353:i1472.

24. Office of Health Economics. shedding the Pounds: obesity management, NICE guidance and bariatric surgery in England. 2011 https://www.rcseng.ac.uk/news/docs/BariatricReport. pdf.

25. Owen-Smith A, Kipping R, Donovan J, et al. A NICE example? variation in provision of bariatric surgery in England. $B M J$ 2013;346:f2453.

26. Public Health England. Model based estimates of adult obesity 20062008. 2010 http://datagateway.phe.org.uk/.

27. Department for Communities and Local Government. The English Indices of Deprivation. $2010 \mathrm{http}: / / w w w . c o m m u n i t i e s . g o v . u k /$ publications/corporate/statistics/indices2010.

28. Office for National Statistics. Super output area mid-year population estimates for England and Wales (experimental). Mid-2002 to Mid-2010 revised. 2016 http://www.ons.gov.uk/ons/publications/rereference-tables.html?edition=tcm\%3A77-285154.

29. Padwal RS, Damjanovic S, Schulze KM, et al. Canadian physicians use of antiobesity drugs and their referral patterns to weight management programs or providers: the SOCCER study. $J$ Obes 2011;2011:1-6.

30. Ahmad A, Laverty AA, Aasheim E, et al. Eligibility for bariatric surgery among adults in England: analysis of a national cross-sectional survey. JRSM Open 2014;5:204253331351247.

31. Public Health England. Public Health Outcomes Framework, Indicator 2.17 recorded diabetes. $2012 \mathrm{http}: / / \mathrm{www}$.phoutcomes.info/ public-health-outcomes-framework\#page/9/gid/1000042/pat/6/par/ E12000005/ati/101/are/E08000025/iid/21701/age/187/sex/4.

32. Green MA, Subramanian SV, Razak F. Population-level trends in the distribution of body mass index in England, 1992-2013. J Epidemiol Community Health 2016;70:832-5.

33. Kmietowicz Z. Postcode lottery persists over weight loss surgery despite NICE guidance. BMJ 2010;340:c427.

34. NHS Commissioning Board Clinical Reference Group forSevere and Complex Obesity. Clinical commissioning policy: complex and specialised obesity surgery [Internet]. $2013 \mathrm{http}: / / w w w . e n g l a n d . n h s$. uk/wp-content/uploads/2013/04/a05-p-a.pdf (accessed 2014 Jan 17).

35. Public Health England Obesity \& Healthy Weight Team. Joined up clinical Pathways for Obesity: report of the Working Group [Internet]. 2014 http://www.england.nhs.uk/wp-content/uploads/2014/03/owgjoin-clinc-path.pdf (accessed 12 Feb 2015). 